\title{
A Hierarchical Optimal Operation Strategy of Hybrid Energy Storage System in Distribution Networks with High Photovoltaic Penetration
}

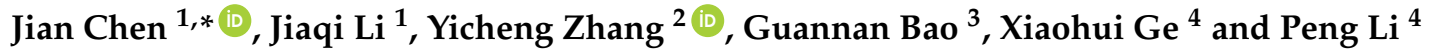 \\ 1 Key Laboratory of Power System Intelligent Dispatch and Control of Ministry of Education, \\ Shandong University, Jinan 250061, China; ljq0324@163.com \\ 2 School of Electrical and Electronic Engineering, Nanyang Technological University, Singapore 639798, \\ Singapore; yzhang088@ntu.edu.sg \\ 3 State Grid Shandong Electric Power Dispatching \& Control Center, Jinan 250001, China; ruby_bgn@163.com \\ 4 Electric Power Research Institute of State Grid Zhejiang Electric Power Co., LTD., Hangzhou 310014, China; \\ gegexiaohui@126.com (X.G.); lipeng_hz@163.com (P.L.) \\ * Correspondence: ejchen@sdu.edu.cn; Tel.: +86-189-5452-8589
}

Received: 20 January 2018; Accepted: 5 February 2018; Published: 7 February 2018

\begin{abstract}
In this paper, a hierarchical optimal operation strategy for a hybrid energy storage system (HESS) is proposed, which is suitable to be utilized in distribution networks (DNs) with high photovoltaic (PV) penetration to achieve PV power smoothing, voltage regulation and price arbitrage. Firstly, a fuzzy-logic based variable step-size control strategy for an ultracapacitor (UC) with the improvement of the lifetime of UC and tracking performance is adopted to smooth PV power fluctuations. The impact of PV forecasting errors is eliminated by adjusting the UC power in real time. Secondly, a coordinated control strategy, which includes centralized and local controls, is proposed for lithium-ion batteries. The centralized control is structured to determine the optimal battery unit for voltage regulation or price arbitrage according to lithium-ion battery performance indices. A modified lithium-ion battery aging model with better accuracy is proposed and the coupling relationship between the lifetime and the effective capacity is also considered. Additionally, the local control of the selected lithium-ion battery unit determines the charging/discharging power. A case study is used to validate the operation strategy and the results show that the lifetime equilibrium among different lithium-ion battery units can be achieved using the proposed strategy.
\end{abstract}

Keywords: hybrid energy storage system (HESS); hierarchical operation strategy; photovoltaic (PV); fuzzy-logic; lifetime equilibrium

\section{Introduction}

Due to the global energy crisis and environmental concerns, the installed capacity of photovoltaics (PVs) in distribution networks (DNs) is increasing rapidly. However, the resulting power fluctuations, voltage violations and other issues have aroused great concern [1,2]. To deal with these problems, energy storage systems (ESSs) have become one of the effective solutions and the hybrid energy storage system (HESS) concept has gained considerable attention because of the complementarity of different types of ESSs [3,4].

The optimal operation strategy of HESS in DNs is a vital and active topic. Recent literatures provide two paths: the first path adopts mathematical optimization methods, such as non-linear programming (NLP) [5], mixed-integer linear programming (MILP) [6], second-order cone programming (SOCP) [7], quadratic programming (QP) [8], etc., and intelligent algorithms, such as genetic algorithm (GA) [9], particle swarm optimization (PSO) [10], etc. For mathematical methods, more complex models and 
constraints often result in an optimization with a non-convex feasible region in which it is difficult to guarantee the convergence to the global optimum. On the other hand, a decent sized population and generations are usually required before obtaining good results for intelligent algorithms [11,12].

The second path adopts heuristic rules methods. Unlike optimization solvers, it is easy to put more complex mathematical models in heuristic rules, which may lead to a more accurate solution. Although the optimal solution is not guaranteed, due to implementation simplicity and good performance in applications, many works have been carried out on this kind of operation strategy. References [13-16] propose different rule-based operation strategies to smooth the renewable energy. In [13], a rule-based control strategy for HESS including vanadium redox battery and ultracapacitor (UC) is proposed for smoothing power fluctuations of large PV plant. The power management is designed to increase HESS efficiency by avoiding battery operating at low power levels. In [14], a control strategy is proposed through decoupling of different frequency power components. Battery and UC are utilized to handle sudden changes of PV and load. Reference [15] proposes a real-time coordinated control algorithm for HESS, which is to eliminate the different term fluctuations by using capacitor and battery. The ramp rate and state of charge (SOC) limitations are also considered in the proposed algorithm. In [16], a wind power filtering approach is proposed to smooth different term fluctuations with HESS. A frequency distribution allocates wind power fluctuations to the different HESS components to satisfy different fluctuation mitigation requirements. The rule-based operation strategies aiming at voltage regulation are proposed in [17-21]. In [17], a coordinated control of ESS with traditional on-load tap changer transformers to deal with the voltage problems brought by large PV is proposed. A coordinated implementation of PV and ESS to solve the voltage violation is proposed in [18], and in urban and rural scenarios, the reactive capability of PV and ESS is evaluated. In [19], a coordinated control strategy including distributed control and local control is proposed for ESS. The distributed control regulates the feeder voltages by consensus algorithm and the local control adjusts SOC of each ESS. References $[18,19]$ noted that DNs usually have larger $\mathrm{R} / \mathrm{X}$ ratios which makes active power more effective in voltage control. In [20], a control strategy, including centralized and decentralized control, for multiple ESSs is proposed for voltage regulations. Reference [21] provides an investigation into the use of ESS for network voltage regulation of a rural feeder. Three different control strategies for the ESS are proposed in different instances. In general, current researches mostly focus on limited objectives which may reduce the effectiveness of utilizing HESS. Moreover, the operation strategy with single objective may lead to heavy workload of certain HESS units, eventually causing unbalanced utilization ratio among different units and resulting in high maintenance cost.

In addition, the lifetime of lithium-ion batteries is an important indicator in the operation strategy design with consideration of its limitations and economic issues. In recent literatures, the cumulative throughput model is adopted to estimate the lifetime of lithium-ion battery because of its simplicity $[22,23]$. However, this model ignores the influences of the charging/discharging rate, temperature and other external factors which limits the evaluating accuracy. Some models with better accuracy have been proposed by relevant researchers who are focusing on the mechanism of lithium-ion battery. Reference [24] adopts a power law equation to establish a life model that accounts for ampere-hour throughput (time), charging/discharging rate, and temperature. In [25], the authors propose a semi-empirical lithium-ion battery degradation model by combining some fundamental theories of the battery degradation with battery aging test results. These studies provide a good reference and facilitate the performance improvements of the operation strategy.

In this paper, a rule-based hierarchical operation strategy of HESS, including lithium-ion batteries and UCs, for PV power smoothing, voltage regulation, and price arbitrage is proposed. For some DNs with large $\mathrm{R} / \mathrm{X}$ ratios, the regulation effects of active power are more significant. Therefore, the active power of HESS is mainly considered in the proposed strategy. Firstly, a fuzzy-logic based variable step-size control strategy for UC is proposed to smooth PV power fluctuation which improves the UC lifetime as well as the tracking performance. The impact of PV forecasting error is eliminated by adjusting UC power in real time. Secondly, in the coordinated control for lithium-ion battery, 
centralized control selects the optimal battery unit to perform voltage regulation or price arbitrage according to evaluation matrix considering battery performance indices such as State of Charge (SOC), charging/discharging power, remaining lifetime, voltage sensitivity factor (VSF), and voltage cost sensitivity factor (VCSF). The local control of the selected lithium-ion battery unit determines the charging/discharging power. A modified battery aging model with better accuracy is proposed. The main contributions of this paper are summarized as follows:

(1) A multi-objectives hierarchical operation strategy with consideration of PV power smoothing, voltage regulation, and price arbitrage is proposed, which can improve the effectiveness of utilizing HESS.

(2) A fuzzy-logic based variable step-size control strategy is designed for UC to prolong its lifetime and improve the tracking performance simultaneously.

(3) A more accurate aging model of lithium-ion battery considering the influences of solid electrolyte interphase (SEI) film, charging/discharging rate, temperature and other external factors is proposed. The coupling relationship between the lifetime and the effective capacity is also considered.

(4) Due to the consideration of lithium-ion battery lifetime and multi-objectives of HESS, the heavy workload of certain units is avoided and the lifetime equilibrium among different battery units is achieved.

The paper is organized as follows: Section 2 describes the mathematical models of our problem. Section 3 introduces the hierarchical optimal operation strategy for HESS. Finally, the results of case studies and conclusions are presented in Sections 4 and 5, respectively.

\section{Mathematical Models}

\subsection{UC}

The energy stored in $U C E_{c}$ can be calculated based on its terminal voltage:

$$
E_{c}=F_{c} U_{c}^{2} / 2
$$

where $F_{c}$ is the capacitance of $\mathrm{UC}$, and $U_{c}$ is $\mathrm{UC}$ 's terminal voltage. The SOC of UC $S_{c}$ can be expressed as follows:

$$
S_{c}=\frac{F_{c} U_{c}^{2} / 2}{F_{c} U_{c, \text { rated }}^{2} / 2}=\frac{U_{c}^{2}}{U_{c, \text { rated }}^{2}}
$$

where $U_{c, \text { rated }}$ is the rated voltage of UC.

The remaining lifetime of $U C L_{\mathcal{C}}$ is also a critical indicator in the design of operation strategy, and in practice, the cumulative throughput model is often used [26,27]:

$$
L_{c}=1-\frac{\sum\left|P_{c} \Delta t\right|}{E_{c, l i f e}}
$$

where $E_{c, l i f e}$ is the total throughput of UC lifetime, $P_{c}$ is UC's charging/discharging power, $\Delta t$ is the charging/discharging period.

\subsection{Tracking Performance Indicator}

In this paper, UC is used to smooth PV power and the tracking performance indicator $\delta$ is adopted here:

$$
\delta=\frac{\left|P_{v}-P_{c}-P_{v, r e f}\right|}{P_{v, \text { ref }}} \times 100 \%
$$

where $P_{v}$ is PV power, $P_{v, r e f}$ is the expected reference value of PV power. 


\subsection{Lithium-Ion Battery}

The relationship between capacity degradation of lithium-ion battery and cycle numbers is non-linear. Figure 1 shows that the degradation rate is much higher during the early cycles because of the formation of SEI film [28]. After forming a stable SEI, the degradation rate becomes steady which mainly depends on the working conditions of the battery. Considering the influences of SEI film, charging/discharging rate $C$, temperature $T$ and other external factors, the battery remaining life $L_{b}$ can be expressed as [24,25]:

$$
\begin{aligned}
L_{b} & =1-\alpha_{\text {sei }} e^{-f_{\text {sei }}}-\left(1-\alpha_{\text {sei }}\right) B e^{\frac{-a_{1}+a_{2} C}{R T}}\left(\frac{P_{b} \Delta t}{U_{b, \text { rated }}}\right)^{z} / 0.2 E_{b, \text { rated }} \\
& \approx 1-\alpha_{\text {sei }}-\left(1-\alpha_{\text {sei }}\right) B e^{\frac{-a_{1}+a_{2} C}{R T}}\left(\frac{P_{b} b t}{U_{b, \text { rated }}}\right)^{z} / 0.2 E_{b, \text { rated }}
\end{aligned}
$$

where $\alpha_{s e i}$ is the rate of battery's active material which is consumed to form the SEI film. $f_{\text {sei }}$ is a rate related to the formation of the SEI film and $e^{-f s e i}=0$ can be assumed because the process is transient. Parameters $B, a_{1}, a_{2}$ and $z$ are obtained from a large number of lifetime experiments. $R$ is the gas constant. $P_{b}$ is the charging/discharging power of battery. $U_{b \text {,rated }}$ is the rated voltage of battery. $E_{b, \text { rated }}$ is the rated capacity of the battery. According to the IEEE1188-1996 standard, when the capacity loss is more than $20 \%$, the battery has reached the end of its service lifetime.

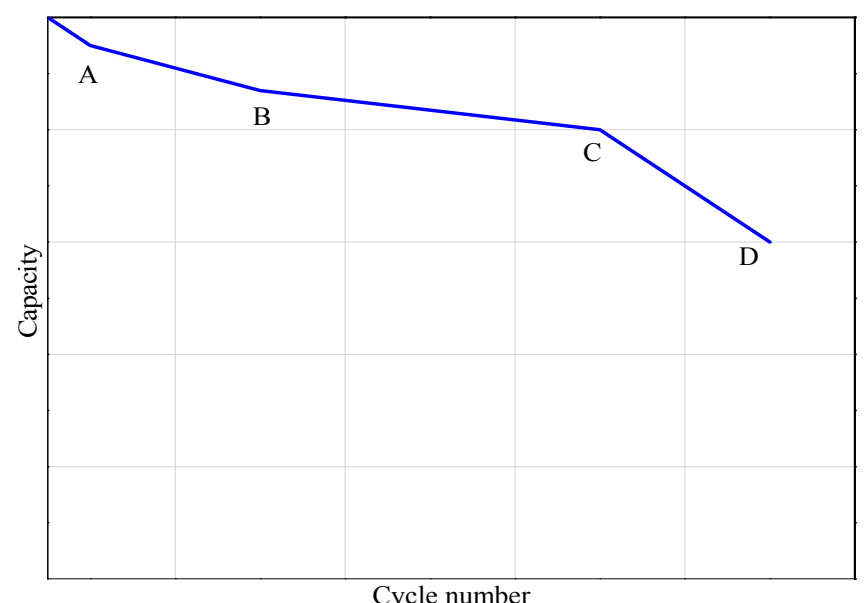

Figure 1. General capacity degradation of lithium-ion battery.

In general, state of health $(\mathrm{SOH})$ is used to evaluate battery health state. When the battery is used for a period of time, there will be capacity fading, and $H_{b}$ can be defined as follows:

$$
H_{b}=\frac{E_{a g e d}}{E_{b, \text { rated }}}=\frac{E_{b, \text { rated }}-0.2 E_{b, \text { rated }}\left(1-L_{b}\right)}{E_{b, \text { rated }}}=0.8+0.2 L_{b}
$$

where $E_{\text {aged }}$ is the effective capacity of the battery.

\subsection{Voltage Control Indicator}

In this paper, lithium-ion battery is used to voltage regulation. The VSF describes the degree of voltage changes at a specified location triggered by the variation in nodal active or reactive power. For radial DNs, due to the focus on voltage magnitude, the sensitivity factor matrix can be simplified as [29]:

$$
\Delta V_{i}=\left[\begin{array}{ll}
V S F_{P i j} & V S F_{Q i j}
\end{array}\right]\left[\begin{array}{c}
\Delta P_{j} \\
\Delta Q_{j}
\end{array}\right]
$$


where $V S F_{P i j}=\Delta V_{i} / \Delta P_{j}$ and $V S F_{Q i j}=\Delta V_{i} / \Delta Q_{j}$, it means the effect of active power $\Delta P_{j}$ or reactive power $\Delta Q_{j}$ variation in nodal $j$ to the node $i$ voltage variation $\Delta V_{i}$.

The VCSF is used to describe the cost associated with voltage control measures. The VCSF is derived as a function of the voltage sensitivities and voltage control costs. For example, the VCSF is of voltage control measure $s$ to node $i$ is defined as [30]:

$$
V C S F_{i s}=\frac{\Delta V_{i}}{C_{S}}
$$

where $C_{s}$ is the cost of voltage control measure $s$ corresponding to node $i$ voltage change $\Delta V_{i}$.

\subsection{HESS Profit}

The price arbitrage, cost of voltage violation and profit of postpone the grid upgrading are chosen as the HESS economic evaluation indicators. With consideration of the HESS installation, operation and maintenance costs, and government subsidies, the HESS profit $f$ is defined as [31,32]:

$$
\begin{aligned}
f & =\sum_{d=1}^{365} \sum_{t=1}^{24} P_{\text {grid }}(t) f_{e}(t)-\sum_{d=1}^{365} \sum_{t=1}^{24} P_{\text {grid,no }}(t) f_{e}(t)+\lambda_{d} f_{d} \eta P_{b, \text { rated }} \\
& +\sum_{d=1}^{365} \sum_{t=1}^{24} P_{b}(t) f_{\text {sub }}-\sum_{d=1}^{365} \sum_{t=1}^{24} \sum_{i=1}^{N} A_{i}(t) f_{v} \sqrt{\left|V_{i}(t)^{2}-V_{\text {ref }} f^{2}\right|} \\
& -\lambda_{p} f_{p} P_{b, \text { rated }}-\lambda_{e} f_{e} E_{b, \text { rated }}-\lambda_{c} f_{c} F_{c}-f_{m} P_{b, \text { rated }}
\end{aligned}
$$

where $P_{\text {grid }}$ and $P_{\text {grid,no }}$ are the interactive power between the DN and the main grid with and without batteries, respectively. $P_{b \text {,rated }}$ is the rated power of the battery. $f_{e}, f_{s u b}$ and $f_{v}$ are the real-time price, the government subsidy price and the voltage violation cost coefficient, respectively. $\lambda_{d}, \lambda_{p}, \lambda_{e}$ and $\lambda_{c}$ are the annual fixed assets depreciation rate of DN equipment, power conversion equipment, battery and $\mathrm{UC}$, respectively. $f_{d}, f_{p}, f_{e}, f_{c}$ and $f_{m}$ are the unit capacity cost of DN equipment, power conversion equipment, battery, UC and maintenance cost, respectively. $\eta$ is the efficiency factor of the battery. $N$ is the total number of nodes. $V_{\text {ref }}$ is the node voltage reference value. $A_{i}$ is a binary variable, when $V_{i}$ is within the limits, $A_{i}=0$, otherwise $A_{i}=1$.

\section{Proposed Operation Strategy}

The structure of the proposed hierarchical operation strategy of HESS is shown in Figure 2. It includes a fuzzy-logic based variable step-size control strategy for PV power smoothing and real-time adjustment strategy for PV forecasting error elimination in the UC, and a voltage regulation and price arbitrage strategy for lithium-ion batteries. The UC charging/discharging power $P_{c}$ and tracking performance indicator $\delta$ calculated by PV forecasting data are the inputs of the fuzzy-logic controller to determine UC control step-size $T_{\mathcal{C}}$ for PV power smoothing. Then UC adjusts its charging/discharging power to eliminate the impact from the PV forecasting error in real-time control strategy. The control commands of $P_{c}$ and $T_{c}$ are sent to the bidirectional converters to control the UC unit while the SOC of UC $S_{c}$ feeds back to the control strategy. For lithium-ion battery, the voltage regulation only operates when node voltage violation occurs, otherwise the price arbitrage is preferred. The centralized control selects the optimal battery unit according to the evaluation matrix considering battery performance indices such as SOC, charging/discharging power, lifetime, VSF, and VCSF. The local control of the selected unit determines its charging/discharging power and communicates with the bidirectional converter for battery unit control. The details of the proposed strategy are presented in the following sections. 


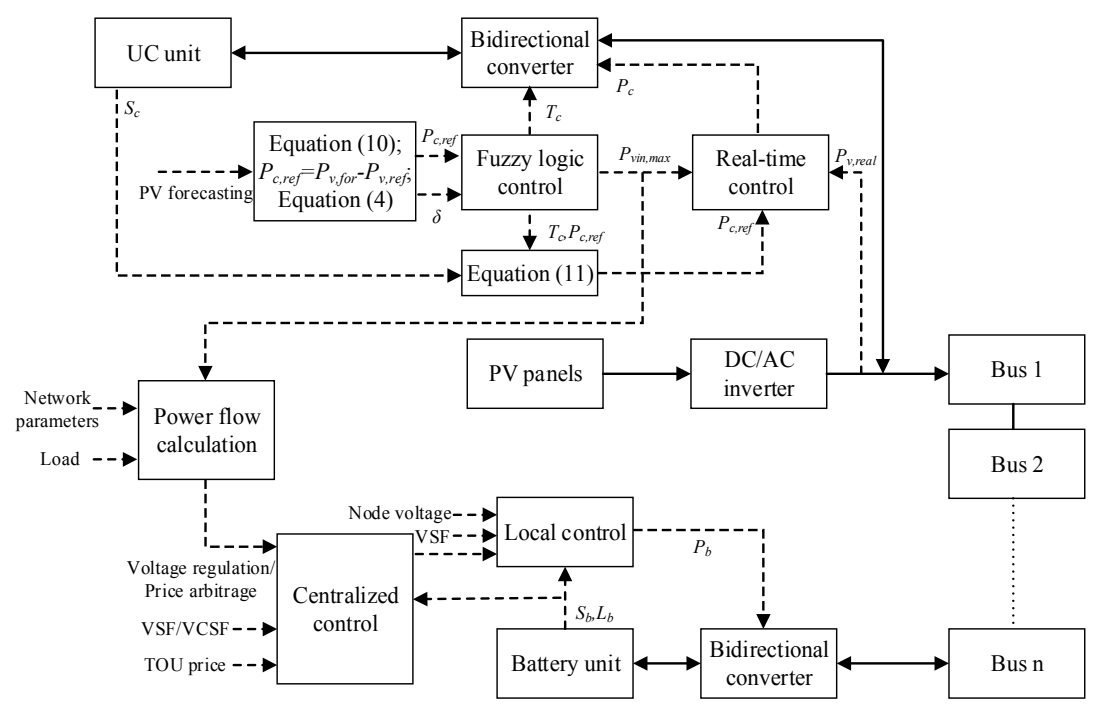

Figure 2. Structure of the hierarchical operation strategy.

\subsection{UC Control Strategy}

An UC has the advantages of high power density, fast charging/discharging speed and long cycle lifetime [33]. Therefore, an UC can respond flexibly and quickly on a short-time scale for smoothing PV power fluctuation and eliminating the influence of PV forecasting error during real-time operation. The details of the proposed operation strategy of UC can be summarized as below.

\subsubsection{PV Power Smoothing}

The control objective of this part is to smooth PV power fluctuation to reduce its impacts on DNs. According to the cumulative throughput model in Equation (3), the remaining lifetime of UC is closely related to its charging/discharging power $P_{c}$ and step-size $T_{c}$. What's more, the tracking performance indicator $\delta$ is also affected by $T_{c}$ which can be optimized to improve tracking performance and prolong UC's service lifetime. Therefore, a variable step-size control strategy for PV power smoothing is proposed. Because of the difficulty to describe the logical relationship among $P_{c}, \delta$ and $T_{c}$ with mathematical formulas, a fuzzy-logic control is designed to adjust the step-size in this paper.

Seven fuzzy sets of the input $P_{c}$, i.e., (DH, DM, DL, ZE, CL, CM, and CH) and $\delta$, i.e., (ZE, LS, MS, $\mathrm{HS}, \mathrm{LB}, \mathrm{MB}$, and $\mathrm{HB})$ are designed. The output $T_{\mathcal{c}}$ has six fuzzy sets, i.e., $(\mathrm{mf} 1, \mathrm{mf} 2, \mathrm{mf} 3, \mathrm{mf} 4, \mathrm{mf} 5$ and mf6). The membership functions of the inputs and output are shown in Figure 3. When $\delta$ is small, it means the PV power injected to the grid $P_{v, \text { in }}\left(P_{v, \text { in }}=P_{v}-P_{c}\right)$ tracks the reference value $P_{v, \text { ref }}$ well. And at this time, the step-size is chosen according to $P_{c}$. If $\left|P_{c}\right|$ is large, a shorter $T_{c}$ will be expected; otherwise, a longer one. When $\delta$ is large, the quality of $P_{v, \text { in }}$ should be prioritized and a smaller $T_{\mathcal{c}}$ is expected to improve $\delta$. The fuzzy-logic control rules are shown in Table 1 .

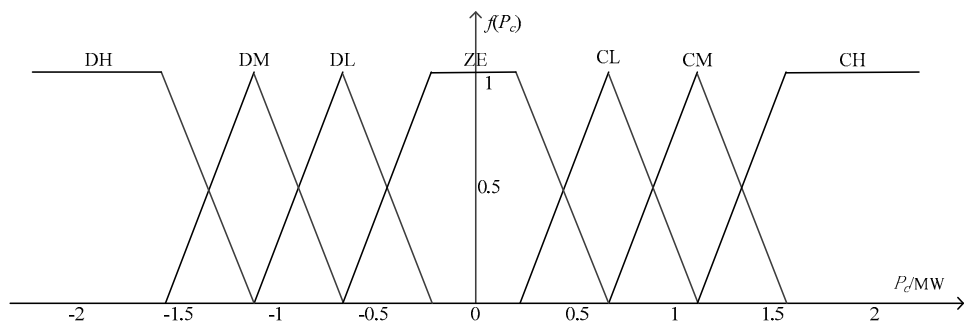

(a)

Figure 3. Cont. 


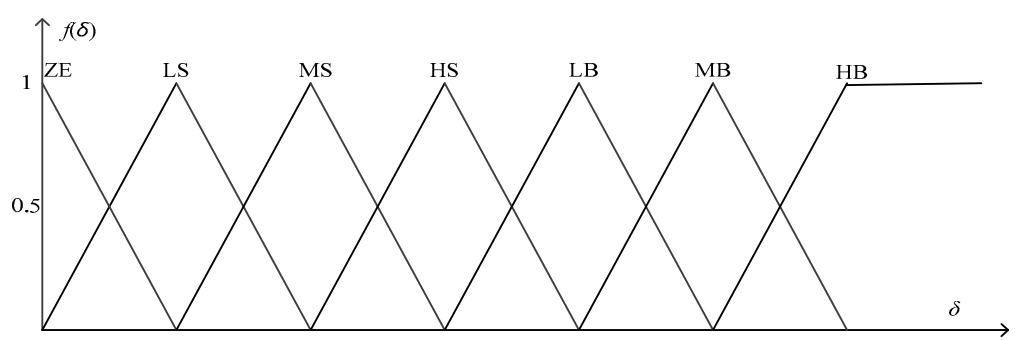

(b)

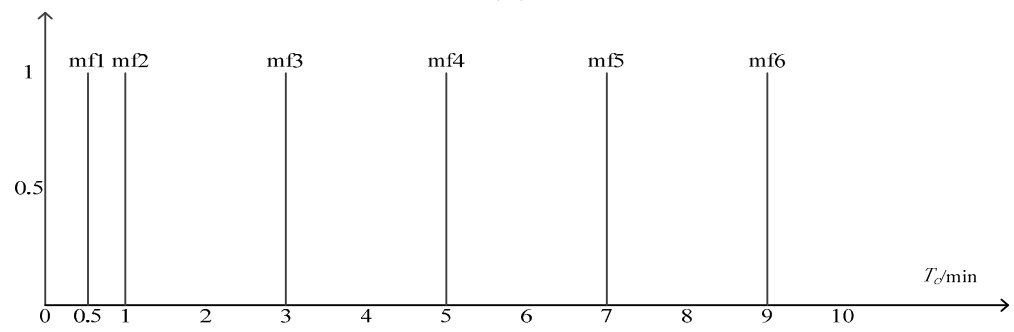

(c)

Figure 3. Membership functions: (a) The membership function of $P_{c} ;(\mathbf{b})$ The membership function of $\delta ;(\mathbf{c})$ The membership function of $T_{c}$.

Table 1. Rules of fuzzy-logic control.

\begin{tabular}{|c|c|c|c|c|c|c|c|}
\hline Sets & DH & DM & DL & ZE & CL & $\mathrm{CM}$ & $\mathrm{CH}$ \\
\hline ZE & mf1 & $\mathrm{mf} 4$ & mf5 & $\mathrm{mf6}$ & mf5 & $\mathrm{mf} 4$ & mf1 \\
\hline LS & mf1 & $\mathrm{mf} 3$ & mf5 & $\mathrm{mf6}$ & $\mathrm{mf1}$ & $\mathrm{mf} 3$ & mf1 \\
\hline MS & mf1 & $\mathrm{mf} 3$ & $\mathrm{mf3}$ & $\mathrm{mf} 4$ & $\mathrm{mf1}$ & $\mathrm{mf3}$ & mf1 \\
\hline HS & mf1 & $\mathrm{mf} 2$ & $\mathrm{mf3}$ & $\mathrm{mf} 4$ & mf1 & $\mathrm{mf} 2$ & mf1 \\
\hline LB & $\mathrm{mf1}$ & $\mathrm{mf} 2$ & $\mathrm{mf} 2$ & $\mathrm{mf} 3$ & $\mathrm{mf1}$ & $\mathrm{mf} 2$ & $\mathrm{mf1}$ \\
\hline MB & mf1 & mf1 & $\mathrm{mf} 2$ & $\mathrm{mf3}$ & mf1 & $\mathrm{mf} 2$ & mf1 \\
\hline $\mathrm{HB}$ & mf1 & mf1 & mf1 & $\mathrm{mf1}$ & mf1 & mf1 & mf1 \\
\hline
\end{tabular}

The reference value of PV power $P_{v, \text { ref }}$ is calculated as below:

$$
P_{v, \text { ref }}=\frac{1}{2}\left[P_{v, \text { refpre }}+\frac{1}{r} \sum_{t=0}^{r} P_{v, \text { for }}\left(T_{\text {cur }}+t\right)\right]
$$

where $P_{v, f o r}$ is the PV forecasting data, and $P_{v \text {,refpre }}$ is the previous reference value of PV output. $T_{\text {cur }}$ is the current time parameter, and $r$ is the number of $P_{v, f o r}$ involved when calculating the reference value.

The SOC limits of UC which can be expressed as the terminal voltage limits according to Equation (2) should also be taken into consideration. If the UC terminal voltage $U_{c}$ exceeds the limits, the UC charging/discharging power $P_{c, \text { ref }}$ should be adjusted:

$$
P_{c, \text { ref }}=\left\{\begin{array}{cc}
F_{c}\left(U_{c, \text { max }}^{2}-U_{c}^{2}\right) / 2 T_{c} & \text { Charging } \\
F_{c}\left(U_{c, \text { min }}^{2}-U_{c}^{2}\right) / 2 T_{c} & \text { Discharging }
\end{array}\right.
$$

where $U_{c, \text { max }}$ and $U_{c, \text { min }}$ are the upper and lower limits of the UC terminal voltage, respectively.

\subsubsection{Real-Time Adjustment}

Although the ultra-short-term forecasting can achieve high precision, with an error of 10\% [34], forecasting errors are still inevitable in real-time operation. UCs are ideal for eliminating the impact of PV forecasting errors by adjusting their charging/discharging power due to their characteristics. 
In real-time operation, when the actual value of PV power is larger than the forecast value, the voltage may exceed the upper limit if the UC power remains at the value given by a PV power smoothing strategy based on PV forecasting data. To ensure the voltage security, the power of UC should be adjusted:

$$
P_{c}=\left\{\begin{array}{ccc}
P_{v, \text { real }}-P_{v i n, \text { max }} & \text { if } & P_{v, \text { real }}-P_{c, \text { ref }}>P_{v i n, \text { max }} \\
P_{c, \text { ref }} & \text { otherwise }
\end{array}\right.
$$

where $P_{v, \text { real }}$ is the actual value of PV power in real-time, and $P_{v i n, \text { max }}$ is the maximum value of $P_{v, \text { in }}$ in PV power smoothing strategy which is based on PV forecasting data. $P_{c, \text { ref }}$ is the UC charging/discharging power given by PV power smoothing strategy based on PV forecasting data.

\subsection{Lithium-Ion Battery Control Strategy}

Compared to an UC, a lithium-ion battery has high energy density which it can charge/discharge for a long period [35]. Therefore, lithium-ion batteries are more suitable for voltage regulation and price arbitrage because of the requirement for large energy capacity.

\subsubsection{Voltage Regulation}

The purpose of voltage regulation is to solve the voltage violation problems caused by high PV penetration. The strategy includes centralized and local controls: firstly, the centralized control selects the optimal battery unit according to the evaluation matrix considering battery performance indices such as SOC, charging/discharging power, lifetime, VSF, and VCSF; secondly, the local control of the selected unit determines its charging/discharging power and communicates with the centralized control for subsequent decision-making.

(1) Centralized control: The evaluation matrix of voltage regulation $A_{V}$ is built as bellow:

$$
\begin{aligned}
& A_{V}=S \bullet P \bullet L \bullet V S F_{-} \text {total } \bullet V C S F_{-} \text {total }= \\
& {\left[\begin{array}{lll}
S_{1} & & \\
& \ddots & \\
& & S_{n}
\end{array}\right]\left[\begin{array}{lll}
P_{1} & & \\
& \ddots & \\
& & P_{n}
\end{array}\right]\left[\begin{array}{lll}
L_{1} & & \\
& \ddots & \\
& & L_{n}
\end{array}\right]\left[\begin{array}{lll}
V S F_{-} t_{\text {total }} & & \\
& \ddots & \\
& & V^{\prime} F_{-} t_{t} t a l_{n}
\end{array}\right]\left[\begin{array}{lll}
V C S F_{-} \text {total }_{1} & & \\
& \ddots & \\
& & \text { VCSF_total } \\
& &
\end{array}\right]}
\end{aligned}
$$

To enhance the influences of voltage regulation operation on the node voltage, the battery unit with larger VSF is preferred to be selected. The matrix $S, P$ is related to SOC $S_{b}$ and power $P_{b}$ of battery:

$$
\begin{gathered}
S_{n}=\left\{\begin{array}{lr}
1 & S_{b, \min } \leq S_{b} \leq S_{b, \max } \\
0 & S_{b}<S_{b, \text { min }} ; S_{b}>S_{b, \text { max }}
\end{array}\right. \\
P_{n}=\left\{\begin{array}{rr}
1 & -P_{b, \max } \leq P_{n} \leq P_{b, \max } \\
0 & P_{n}<-P_{b, \max } ; P_{n}>P_{b, \max }
\end{array}\right.
\end{gathered}
$$

where $S_{b, \min }$ and $S_{b, \max }$ are the lower and upper limit of battery SOC, respectively. $P_{b, \max }$ is the limit of charging/discharging power. The matrix $L$ represents battery's remaining life calculated by Equation (5). VSF_total is the voltage sensitivity factor matrix, which is the weighted average of the VSF:

$$
V S F \_ \text {total } n=\sum_{i=1}^{k} \frac{\Delta V_{i}}{\sum_{i=1}^{k} \Delta V_{i}} V S F_{i n}
$$


where $k$ is the number of the nodes which exceed the voltage limits. $\Delta V_{i}$ is the voltage deviation of node $i . V S F_{i n}$ is the voltage sensitivity factor of the battery node $n$ to node $i$. VCSF_total is the voltage cost sensitivity factor matrix, and its calculation can refer to Equation (16):

$$
V C S F_{-} \text {total }_{n}=\sum_{i=1}^{k} \frac{\Delta V_{i}}{\sum_{i=1}^{k} \Delta V_{i}} V C S F_{i n}
$$

where $V C S F_{\text {in }}$ is the voltage cost sensitivity factor of battery installed at node $n$ to node $i$.

(2) Local control: The local control determines its individual charging/discharging power $P_{b}$ according to VSF and node voltage as below:

$$
P_{b}=\sum_{i=1}^{k} \frac{\Delta V_{i}}{\sum_{i=1}^{k} \Delta V_{i}} \frac{\Delta V_{i}}{V S F_{i}}
$$

The limits of battery SOC and charging/discharging power are used to adjust $P_{b}$ calculated by Equation (19). If battery's SOC exceeds limits, the charging/discharging power $P_{b}$ is adjusted as below:

$$
P_{b}=\left\{\begin{array}{lr}
\frac{\left(S_{b, \max }-S_{b}\right) E_{b, \text { rated }}}{T_{b}} & \text { Charging } \\
\frac{\left(S_{b, \min }-S_{b}\right) E_{b, \text { rated }}}{T_{b}} & \text { Discharging }
\end{array}\right.
$$

where $T_{b}$ is the step-size of battery. If $P_{b}$ exceeds its charging/discharging power limits, it needs to be adjusted:

$$
P_{b}= \begin{cases}-P_{b, \max } & \text { if } P_{b}<-P_{b, \max } \\ P_{b, \max } & \text { if } P_{b}>P_{b, \max }\end{cases}
$$

\subsubsection{Price Arbitrage}

Currently, the investment cost of lithium-ion batteries is expensive, which will greatly reduce the utilization value if lithium-ion batteries are only applied to voltage regulation without considering the arbitrage opportunity of time of use (TOU) price. The control objective of this part is to realize price arbitrage by charging at the valley-price period and discharging at the peak-price period under the premise of voltage security. Similar to voltage regulation, the centralized control builds the evaluation matrix and selects the optimal battery unit, and the local control of the selected one determines its charging/discharging power in price arbitrage.

(1) Centralized control: The price arbitrage evaluation matrix $A_{E}$ is built as bellow:

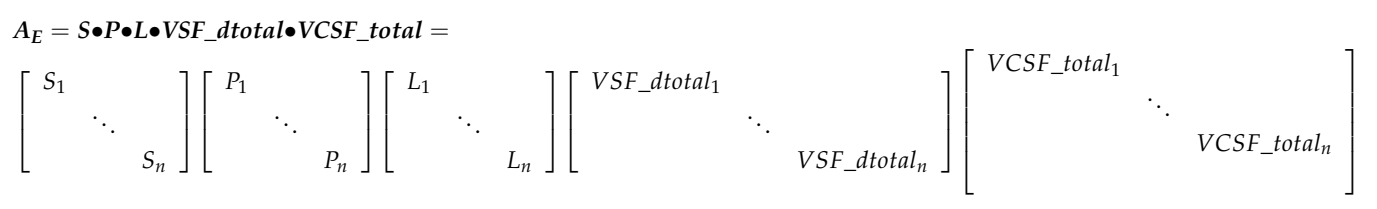

To reduce the influences of price arbitrage operation on the node voltage, the battery with smaller VSF is preferred to be selected. Therefore, the values of VSF are dual to VSF_d between 0 and 1 using the piecewise linear function as below:

$$
V S F \_d=\left\{\begin{array}{cc}
1 & V S F=V S F_{\min } \\
1-\frac{V S F-V S F_{\min }}{V S F_{\max }-V S F_{\min }} & V S F_{\min }<V S F<V S F_{\max } \\
0 & V S F=V S F_{\max }
\end{array}\right.
$$


where $V S F_{\min }$ and $V S F_{\max }$ are the minimum and maximum of $V S F$, respectively. For the calculations of matrix $S, P, L, V S F \_d t o t a l$ and VCSF_total refer to Section 3.2.1.

(2) Local control: To ensure each node voltage is within the limits, the minimum node voltage security margin should be considered when the local controller determines its individual charging/discharging power $P_{b}$ :

$$
P_{b}=\left\{\begin{array}{lr}
\min \frac{\left|V_{i}-V_{\max }\right|}{V S F_{i}} & \text { Charging } \\
-\min \frac{\left|V_{i}-V_{\min }\right|}{V S F_{i}} & \text { Discharging }
\end{array}\right.
$$

where $V_{\max }$ and $V_{\min }$ are the upper and lower limits of the node voltage, respectively. The process of $P_{b}$ adjustment can refer to Equations (19) and (20).

On basis of the proposed HESS operation strategy, the steps for implementation are shown in Figure 4.

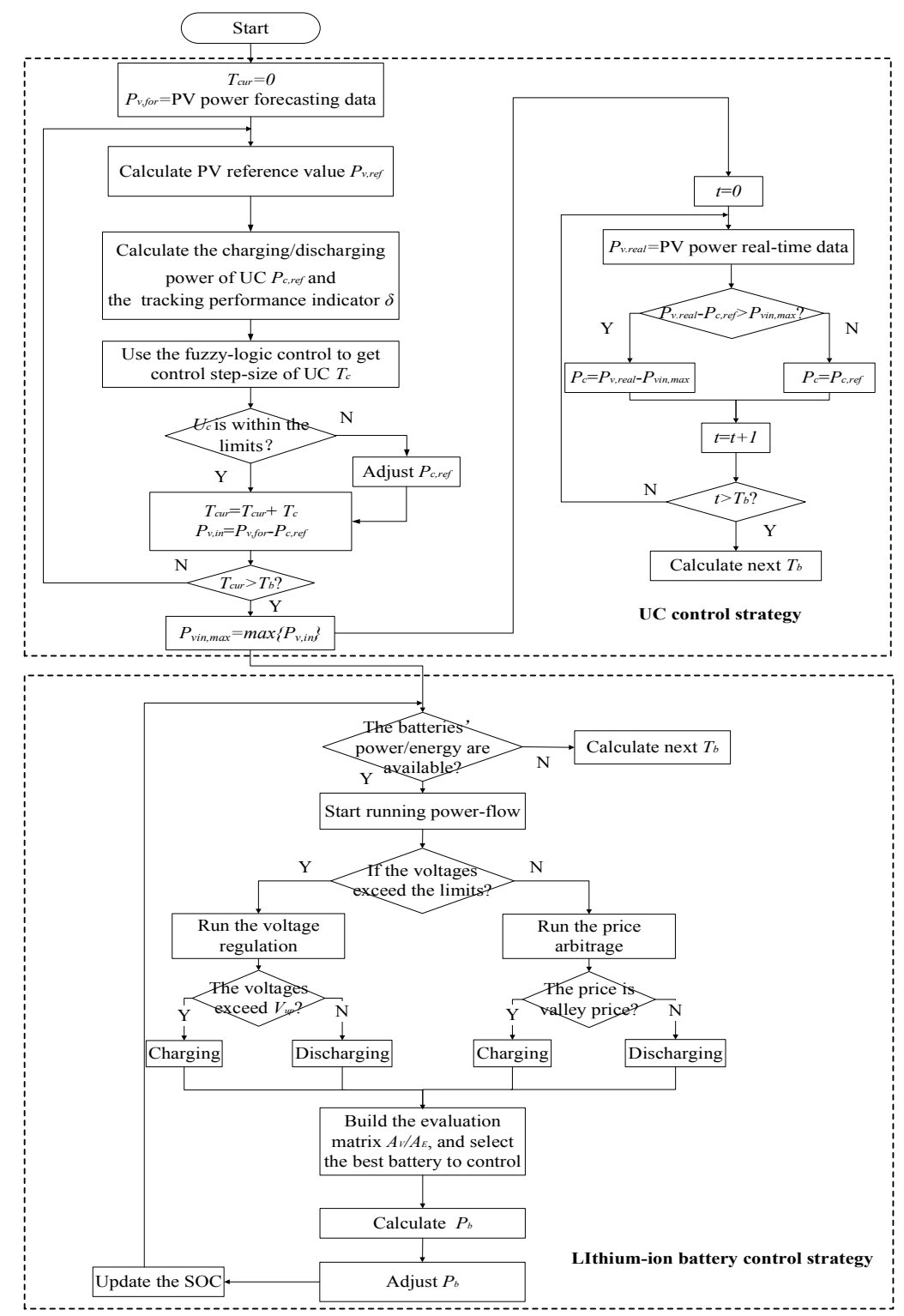

Figure 4. Flowchart of implementation of the method. 


\section{Case Study}

The proposed strategy is tested on a rural DN with 41 buses referring to $[21,36,37]$ which is shown in Figure 5. The power base value is 10 MVA, the demand data are given in Table 2 and the parameters of PV and HESS are given in Table 3. According to GB/T 12325-2008 'power quality and supply voltage deviation', 0.94-1.04 p.u. is selected as the limits of voltage deviations. The peak and valley prices are $0.5583 ¥ / \mathrm{kWh}(8: 00-21: 00)$ and $0.3583 ¥ / \mathrm{kWh}(21: 00-8: 00)$, respectively.

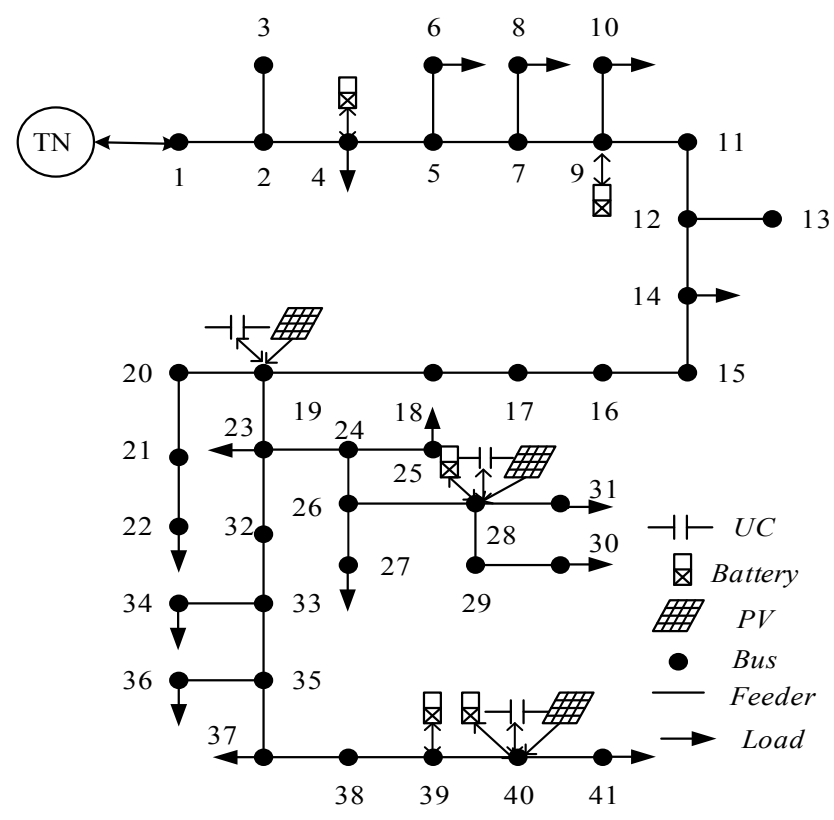

Figure 5. Network for the case study.

Table 2. Demand daily peak and power factors.

\begin{tabular}{cccccc}
\hline Bus & Peak (p.u.) & PF & Bus & Peak (p.u.) & PF \\
\hline 4 & 0.641346 & 0.95 & 25 & 0.028975 & 0.95 \\
6 & 0.089706 & 0.87 & 27 & 0.015200 & 0.95 \\
8 & 0.318725 & 0.95 & 30 & 0.019475 & 0.95 \\
10 & 0.057600 & 0.75 & 31 & 0.051775 & 0.95 \\
13 & 0.001900 & 1.00 & 34 & 0.020425 & 0.95 \\
14 & 0.034675 & 0.95 & 36 & 0.008075 & 0.95 \\
22 & 0.004750 & 0.95 & 37 & 0.010450 & 0.95 \\
23 & 0.000950 & 0.95 & 41 & 0.216600 & 0.95 \\
\hline
\end{tabular}

Table 3. Parameters of PV and HESS.

\begin{tabular}{ccccc}
\hline Battery Location & $\boldsymbol{E}_{\boldsymbol{b}, \text { rated }}$ (p.u.) & $\boldsymbol{P}_{\boldsymbol{b}, \text { rated }}$ (p.u.) & PV/UC Location & $\boldsymbol{P}_{\boldsymbol{v} \text {.rated }}$ (p.u.)/C(MF) \\
\hline 4 & 1.948 & 0.2 & 19 & $0.85 / 0.008$ \\
9 & 1.299 & 0.15 & 28 & $0.4 / 0.004$ \\
28 & 0.844 & 0.1 & 40 & $1.03 / 0.010$ \\
39 & 1.82 & 0.15 & $S_{b, \max } / S_{b, \min }$ & $0.95 / 0.2$ \\
40 & 1.947 & 0.2 & $U_{c, \max } / U_{c, \min }(\mathrm{V})$ & $390 / 200$ \\
\hline
\end{tabular}

In this section, five cases are carried out to verify the effectiveness of the proposed control strategy. The length of the test period of Case 1 to Case 3 is $24 \mathrm{~h}$, and the control step-size of lithium-ion battery is $15 \mathrm{~min}$. The five cases are summarized as below: 
Case 1: The control step-size of UCs is constant, e.g., $1 \mathrm{~min}$, and the batteries are only used for voltage regulation.

Case 2: The control step-size of UCs is constant, e.g., $1 \mathrm{~min}$, and the batteries are used for both voltage regulation and price arbitrage.

Case 3: The control step-size of UCs is adjusted by the fuzzy-logic control, and the operation strategy of batteries is identical with Case 2 .

Case 4: The control strategy of HESS is identical with Case 3. The fault situation, i.e., breakdown of battery unit, is discussed to verify the robustness of the proposed control strategy.

Case 5: The influences of different battery control strategies on battery lifetime are compared in this case and the effects of the lifetime equilibrium among different battery units are shown with different initial lifetime states.

\subsection{Case 1}

In this case, the control step-size of UC is constant, e.g., $1 \mathrm{~min}$, which means the charging/discharging power of the UC $P_{c}$ updates every minute according to $P_{v}$ and $P_{\text {ref. }}$. The batteries are only used for voltage regulation. That is, when all the node voltages are within the limits, the control of lithium-ion battery will not be triggered.

Figure 6 shows the curves of node voltages of different cases. In Figure 6a, from 10:00 to 14:00, the PV power is much larger than the load because of the intense solar radiation which eventually leads to the node voltage violation. During 18:00-22:00, the PV power is zero, but the load is heavy, so the voltage violation occurs and there are 28 nodes' voltages violating the lower limit with the peak load at 20:00. In Figure 6b, the voltage issues are solved by the introducing of HESS.

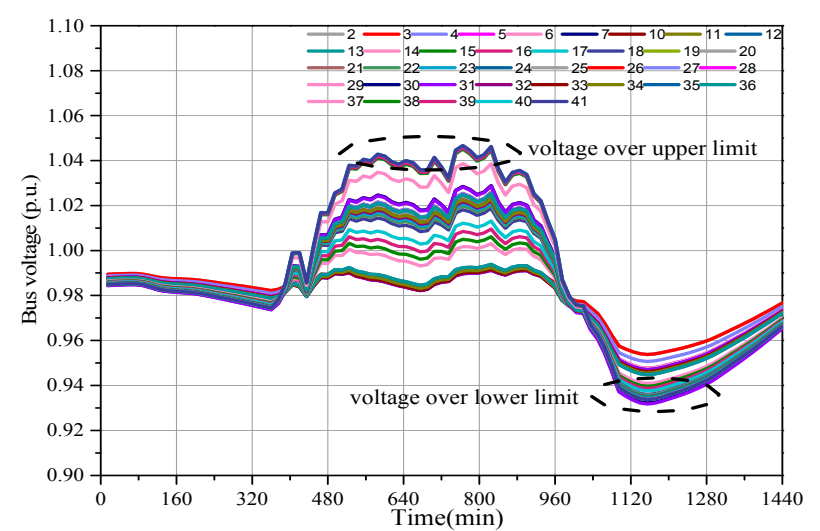

(a)

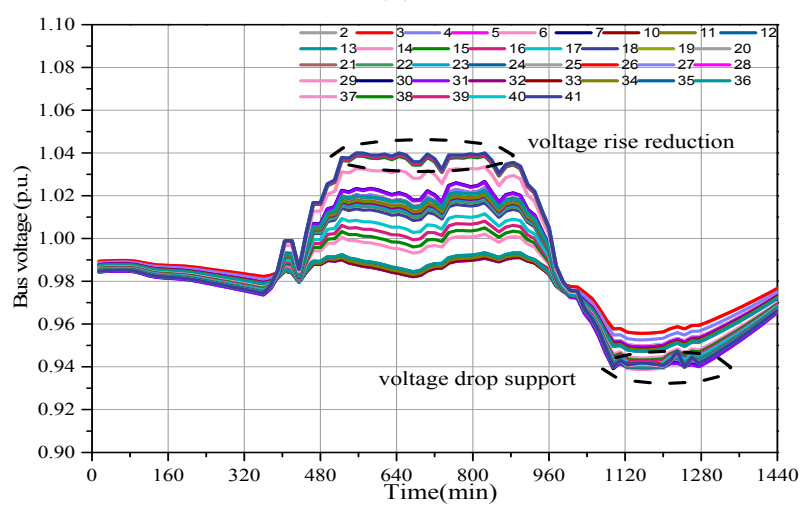

(b)

Figure 6. Cont. 


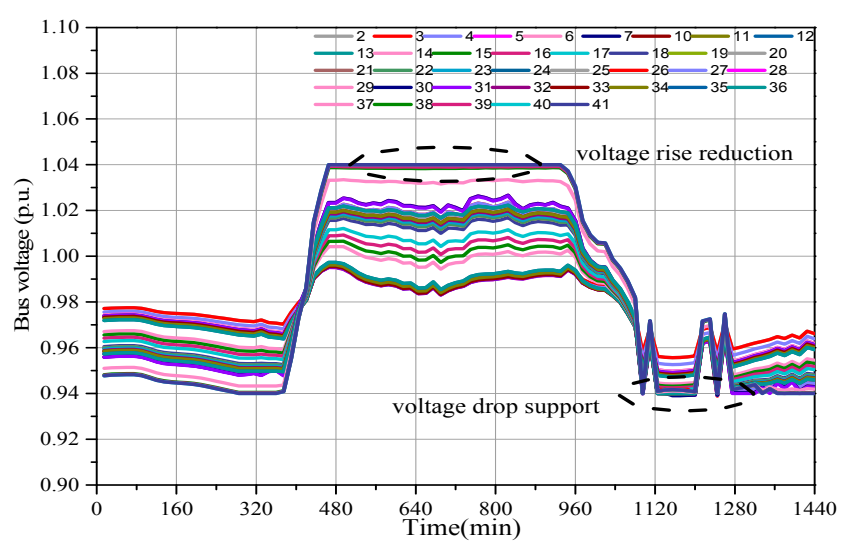

(c)

Figure 6. Curves of node voltages: (a) Node voltages in the case without batteries; (b) Node voltages in Case $1 ;$ (c) Node voltages in Case 2.

\subsection{Case 2}

From Figure $6 c$, to realize price arbitrage, the batteries are preferring to charge in the valley price period (21:00-8:00) and discharge in the peak price period (8:00-21:00) while keeping the voltage within the limits. The annual HESS profit is calculated and the economic comparison is shown in Table 4 .

Table 4. Economic comparison.

\begin{tabular}{ccc}
\hline Cases & HESS Total Investment/10 k¥ & Annual Profit/10 k¥ \\
\hline Without batteries & 4840 & -2244.715 \\
Case 1 & 22956 & -2068.572 \\
Case 2 & 22956 & -1940.525 \\
\hline
\end{tabular}

In the case without batteries, the punishment cost of voltage violation is high, even though there are no investments for batteries. The annual profit is still less than that in Case 1 and Case 2. Because of price arbitrage operations, the gains in Case 2 are significantly improved, and the annual profit is $128.047 \mathrm{k} ¥$ more than that in Case 1. However, as shown in Table 4, the current annual profits of three cases are all negative because the HESS cost is high and energy conversion efficiency is low and the difference between peak and valley price is not large enough compared with the developed countries, where the on-peak electric price can be 4 to 5 times higher than the off-peak price. The relationship between Case 2 annual profit and two influencing factors (unit capacity cost of battery $f_{e}$ and the difference between peak and valley price $f_{\text {peak }}-f_{\text {vally }}$ ) is shown in Figure 7. With the development of technology and the improvement of relevant support policies, the economy of HESS will be further improved. 


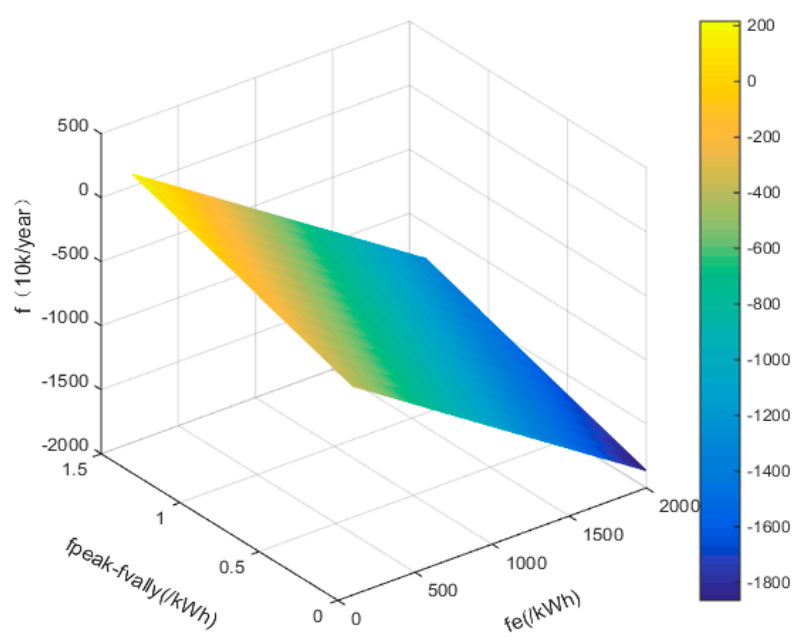

Figure 7. Relationship between annual profit and two influencing factors.

\subsection{Case 3}

In Case 3, the battery control part is identical with Case 2, so the results of voltage regulation and price arbitrage are not repeated here.

Figure 8 shows the results of PV power smoothing and real-time adjustment of UC during 11:00-12:00. $P_{v, \text { real }}$ and $P_{v, \text { for }}$ are the real-time and forecasting data of PV power, respectively. $P_{c, \text { real }}$ and $P_{c, \text { ref }}$ are the charging/discharging power of UC based on the actual and forecasting data of PV power, respectively. When $\left|P_{c}\right|$ is large, the control step-size is smaller, otherwise the control step-size is larger. This obeys the rules of the fuzzy-logic control, and the effects of UC variable step-size control strategy on its remaining life $L_{c}$ and tracking performance indicator $\delta$ are shown in Table 5. According to Equations (3) and (4), the more $\sum\left|P_{c} T_{c}\right|$ and $\delta$ is close to zero, the better that the lifetime state and tracking performance of UC will be. From Table 5, when the control step-size is $1 \mathrm{~min}$, the tracking performance is the best, but the value of $\sum\left|P_{c} T_{c}\right|$ is about 1.5 times of variable step-size control. When the control step-size increases, both of $\sum\left|P_{c} T_{c}\right|$ and $\delta$ are larger than variable step-size control. And the variable step-size control strategy has better performance both on the improvement of UC lifetime and tracking performance.

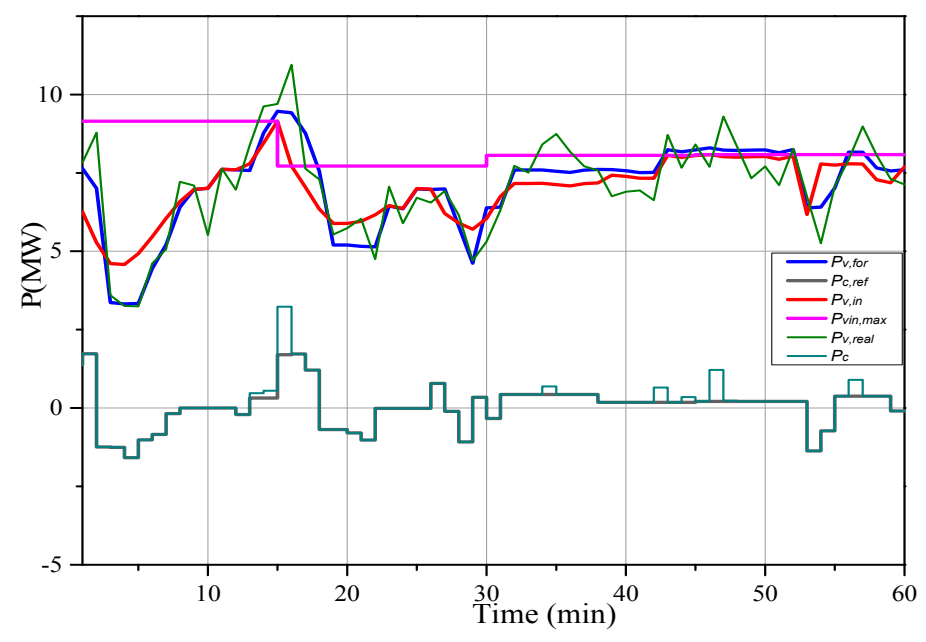

Figure 8. Results of UC control and real-time adjustment. 
Table 5. Effects on $\sum\left|P_{\mathcal{c}} T_{\mathcal{c}}\right|$ and $\delta$.

\begin{tabular}{ccccccc}
\hline \multirow{2}{*}{$\boldsymbol{P}_{\text {v.rated }} / \mathbf{M W}$} & Index & $\begin{array}{c}\mathbf{1} \mathbf{~ m i n} \\
\text { Step-Size }\end{array}$ & $\begin{array}{c}\mathbf{2} \text { min } \\
\text { Step-Size }\end{array}$ & $\begin{array}{c}\mathbf{5} \text { min } \\
\text { Step-Size }\end{array}$ & $\begin{array}{c}\mathbf{1 0} \mathbf{~ m i n} \\
\text { Step-Size }\end{array}$ & $\begin{array}{c}\text { Variable } \\
\text { Step-Size }\end{array}$ \\
\hline \multirow{2}{*}{8.5} & $\sum\left|P_{c} T_{c}\right| / \mathrm{MWh}$ & 3.946 & 3.935 & 4.444 & 5.055 & 2.5548 \\
& $\delta / \%$ & 0 & 3.205 & 8.129 & 11.915 & 3.125 \\
\hline \multirow{2}{*}{4} & $\sum\left|P_{c} T_{c}\right| / \mathrm{MWh}$ & 1.857 & 1.852 & 2.091 & 2.379 & 1.249 \\
& $\delta / \%$ & 0 & 3.205 & 8.129 & 11.915 & 0.8227 \\
\hline \multirow{2}{*}{10.3} & $\sum\left|P_{c} T_{c}\right| / \mathrm{MWh}$ & 4.782 & 4.768 & 5.385 & 6.125 & 3.0061 \\
& $\delta / \%$ & 0 & 3.205 & 8.129 & 11.915 & 0.7614 \\
\hline
\end{tabular}

\subsection{Case 4}

In Case 4, the operation strategy of HESS is identical with the strategy in Case 3. To verify the robustness of the proposed control strategy, a fault situation is analyzed, i.e., a fault occurs and the battery unit installed on bus 4 does not response for one whole day. As shown in Figure 9, although the curves of node voltages are different from the case with all the battery units in Figure 6c, the voltage security is maintained with the proposed control strategy. However, because of the reduction of the total charging/discharging energy of batteries, the daily profit decreases comparing to Case 3 which is shown in Table 6. In all, the available batteries are settled optimally to solve voltage violation problems in Case 4. Furthermore, in some serious faults, PV power curtailment or load shedding may be required to guarantee the voltage security when the capability of the available batteries is insufficient.

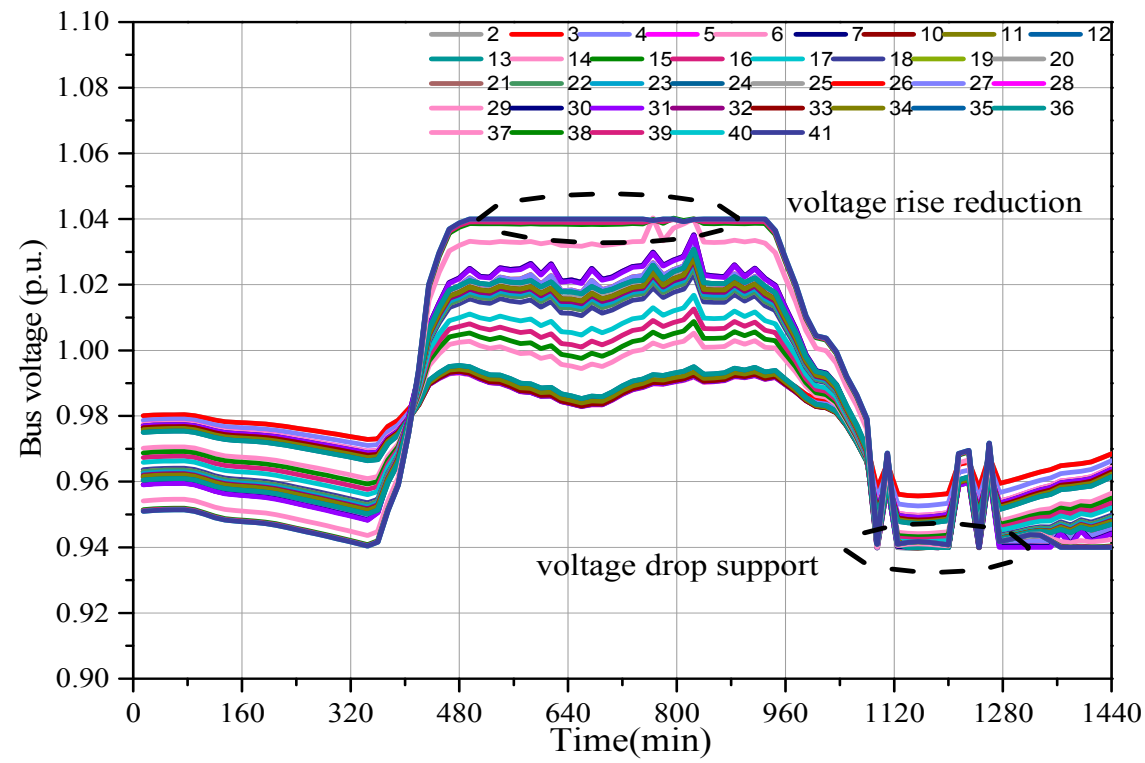

Figure 9. Curves of node voltages in Case 4.

Table 6. Results of price arbitrage.

\begin{tabular}{cc}
\hline Cases & Daily Profit/10 k¥ \\
\hline Case 3 & -5.311 \\
Case 4 & -5.394 \\
\hline
\end{tabular}

\subsection{Case 5}

In Case 5, the operation strategy of HESS is tested for a long period to show the lifetime equilibrium among different battery units. 
According to the characteristics of radial DNs, the voltage deviation of the terminal node is usually large. Therefore, in the process of voltage regulation, the batteries at the end of the line are used frequently which causes the unbalanced utilization rate. With the price arbitrage process, the batteries installed at the beginning of the line are also utilized fully because of the small VSFs. Therefore, the utilization ratios among different battery units are balanced with the proposed operation strategy which combines voltage regulation and price arbitrage. This is beneficial to the average battery lifetime. In Figure 10a, the batteries only operate voltage regulation and the differences among their utilization ratios are large. However, in Figure 10c, where the proposed operation strategy is adopted, when the remaining lifetime of battery installed at node 4 is the same as that in Figure 10a, the lifetime differences among different battery units are smaller. Figure 10b,d show the curves of batteries SOC during one day when they are used for voltage regulation and both voltage regulation and price arbitrage, respectively. It is shown that the batteries at the beginning of the line (battery 4 , battery 9) are almost not used in Figure 10b, and it eventually leads to the unbalanced utilization rates between different battery units in Figure 10a.

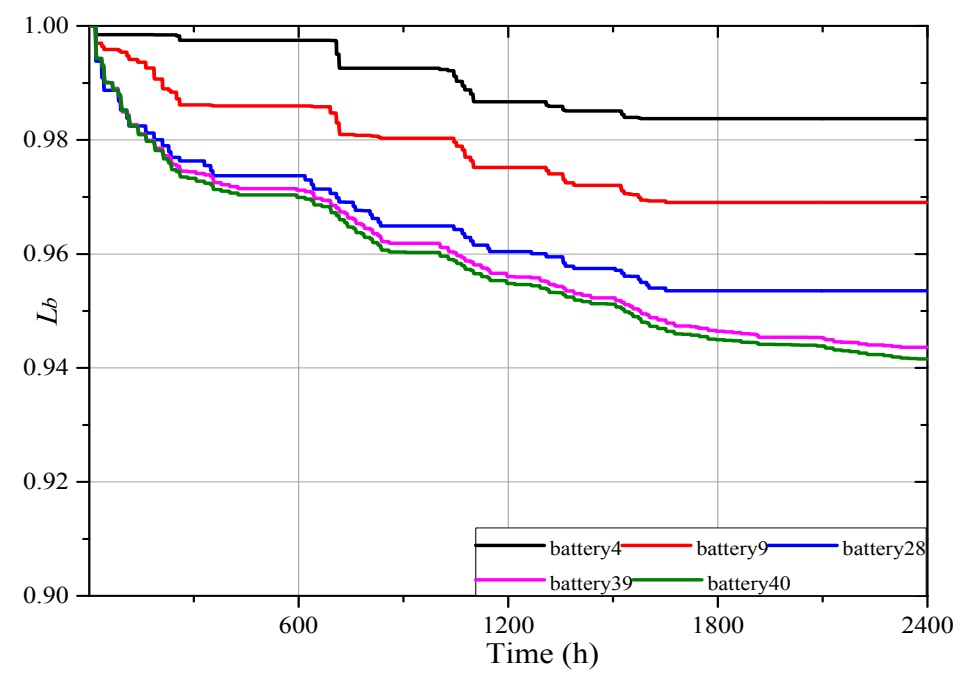

(a)

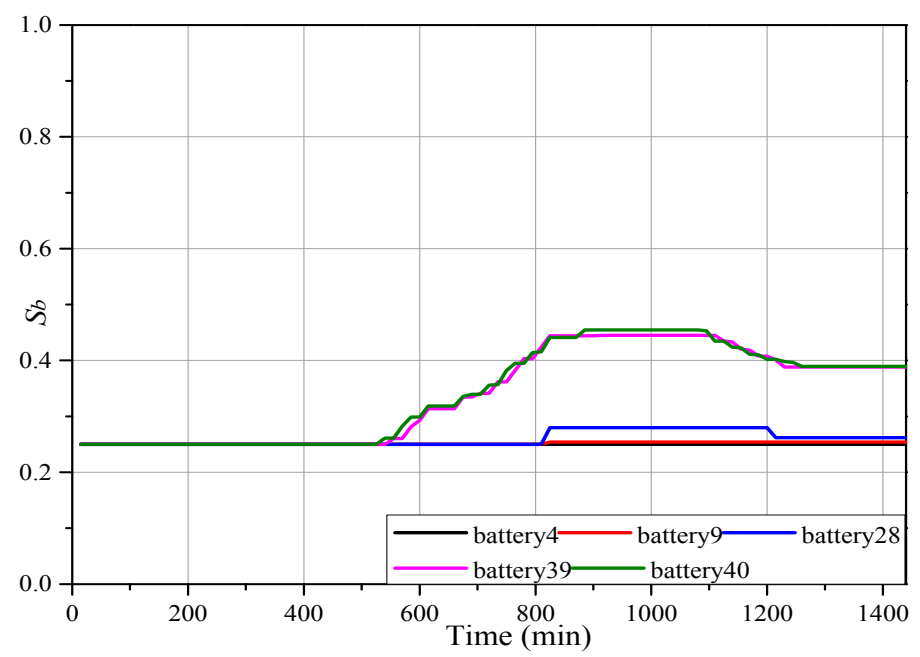

(b)

Figure 10. Cont. 


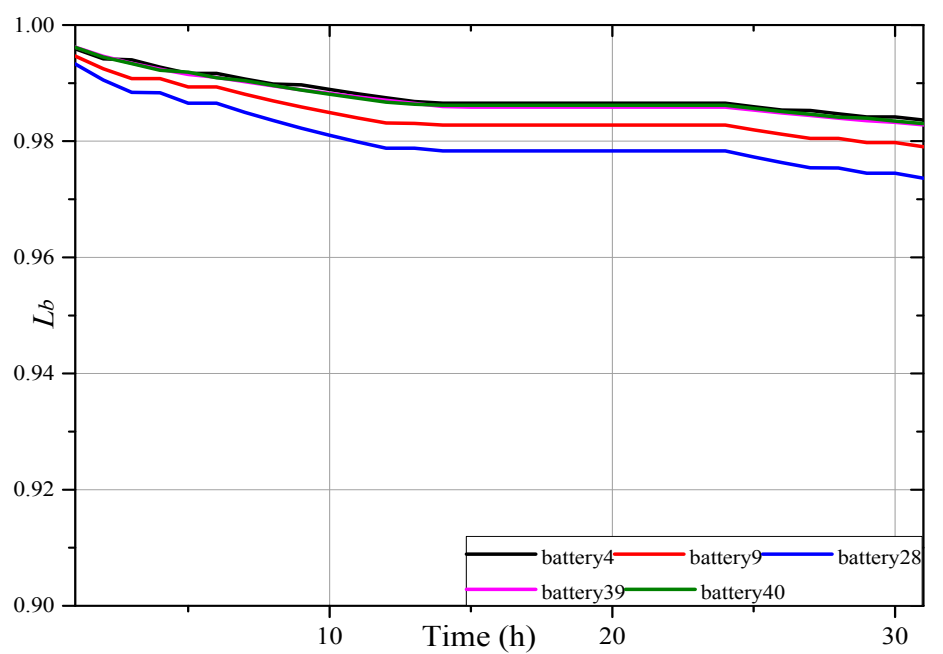

(c)

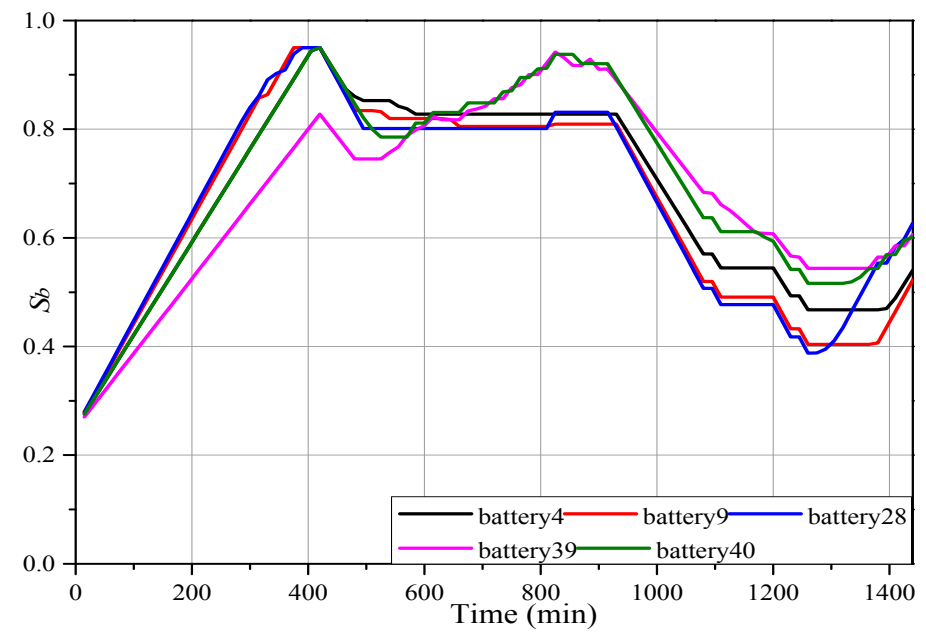

(d)

Figure 10. Curves of batteries: (a) Lifetime $L_{b}$ of batteries only used for voltage regulation; (b) SOC $S_{b}$ of batteries only used for voltage regulation; (c) Lifetime $L_{b}$ of batteries used for voltage regulation and price arbitrage; (d) SOC $S_{b}$ of batteries used for voltage regulation and price arbitrage.

In addition, the battery lifetime is considered in the lithium-ion battery control strategy when selecting the optimal battery units. Based on this, the working conditions of different battery units are optimized according to different lifetime states. The proposed operation strategy is carried out with identical or different initial life states for one year. Table 7 shows the results and $E_{b}$ is the charging/discharging energy of battery. Compared to cases with the same initial lifetime states, when the initial lifetime states are different, the charging/discharging energies of batteries installed on bus 4, 9 and 28 increases significantly, since for those batteries their initial lifetimes are longer than those installed on bus 39 and 40. Similarly, the utilization of the batteries installed on bus 39 and 40, whose initial lifetimes are shorter, will decrease accordingly. As a summary, the utilization ratios of the batteries with short initial lifetime will decrease, and the utilization ratio of the batteries with long initial lifetime will increase to achieve the equilibrium with the proposed operation strategy. Thus, it would benefit the achievement of lifetime equilibrium and the whole system operation. 
Table 7. Results of Case 5.

\begin{tabular}{ccccc}
\hline Number & Initial $L_{\boldsymbol{b}}$ & Annual $\sum E_{\boldsymbol{b}} / \mathbf{M W h}$ & Initial $L_{\boldsymbol{b}}$ & Annual $\sum E_{\boldsymbol{b}} / \mathbf{M W h}$ \\
\hline Battery 4 & 1 & 8289.305 & 1 & 8982.108 \\
Battery 9 & 1 & 6513.481 & 0.92 & 6624.644 \\
Battery 28 & 1 & 3743.667 & 0.95 & 4221.285 \\
Battery 39 & 1 & 7776.123 & 0.9 & 7612.807 \\
Battery 40 & 1 & 8739.034 & 0.8 & 7962.749 \\
\hline
\end{tabular}

\section{Conclusions}

This paper proposes a hierarchical operation strategy of HESS in DNs with high PV penetration for PV power smoothing, voltage regulation, and price arbitrage. A fuzzy-logic based variable step-size control strategy and real-time adjustment are designed for UC. A coordinated control, including centralized and local controls, is proposed for lithium-ion battery to perform voltage regulation and price arbitrage. The results of case studies indicate that:

(1) Compared with the control strategies with fixed step-sizes, e.g., $1 \mathrm{~min}, 2 \mathrm{~min}, 5 \mathrm{~min}, 10 \mathrm{~min}$, the proposed variable step-size control strategy for UC can achieve better performance both on improvements of UC lifetime and tracking performance.

(2) With the coordinated control for voltage regulation and price arbitrage, the economic benefits of lithium-ion battery can be improved by making best use of the price difference of peak and valley electricity without voltage violations. Although the cost of lithium-ion battery is still in a high level, the economic will be further improved with technology development and relevant support polices in the future.

(3) In the case of faults, the proposed control strategy has good robustness to guarantee the voltage security by making full use of the available batteries. However, the economy decreases because of the reduction of the available energy capacity. Furthermore, other measures, e.g., PV power curtailment or load shedding, may be needed to maintain normal operation in some events of serious faults.

(4) With consideration of multi-objectives and lifetime characteristics, the lifetime equilibrium among different lithium-ion battery units can be achieved. The battery units with long lifetime have the priority in utilization while the battery units with short lifetime will be less used which could benefit the whole system operation.

This paper only discussed the operation problems of HESS under the determined configuration. And the optimal siting and sizing is another important topic which will be studied in our future work.

Acknowledgments: The authors would like to thank the support by the National Natural Science Foundation of China (No. 51507094) and State Grid Zhejiang Electric Power Company Project (No. 5211DS15002A, Coordination control of active distribution/microgrid containing multitype distribution generation, energy storage and controllable load).

Author Contributions: Jian Chen and Jiaqi Li conceived and designed the study; Jiaqi Li analyzed the data and prepared the first draft of this manuscript; Jian Chen, Yicheng Zhang and Guannan Bao reviewed and edited the manuscript. While Xiaohui Ge and Peng Li provided technical and financial support throughout. All authors read and approved the manuscript.

Conflicts of Interest: The authors declare no conflict of interest.

\section{References}

1. Woyte, A.; Van, T.V.; Belmans, R.; Nijs, J. Voltage fluctuations on distribution level introduced by photovoltaic systems. IEEE Trans. Energy Convers. 2006, 21, 202-209. [CrossRef]

2. Thomson, M.; Infield, D.G. Impact of widespread photovoltaics generation on distribution systems. IET Renew. Power Gener. 2007, 1, 33-40. [CrossRef] 
3. Fathima, A.H.; Palanisamy, K. Optimization in microgrids with hybrid energy systems-A review. Renew. Sustain. Energy Rev. 2015, 45, 431-446. [CrossRef]

4. Bernhard, F.; Michael, S.; Markus, P.; Peter, K. Battery storage systems as grid-balancing measure in low-voltage distribution grids with distributed generation. Energies 2017, 10, 2161. [CrossRef]

5. Jayasekara, N.; Masoum, M.A.S.; Wolfs, P.J. Optimal operation of distributed energy storage systems to improve distribution network load and generation hosting capability. IEEE Trans. Sustain. Energy 2015, 7, 250-261. [CrossRef]

6. Khani, H.; Zadeh, M.R.D. Online adaptive real-time optimal dispatch of privately owned energy storage systems using public-domain electricity market prices. IEEE Trans. Power Syst. 2014, 30, 930-938. [CrossRef]

7. Qin, M.; Chan, K.W.; Chung, C.Y.; Luo, X.; Wu, T. Optimal planning and operation of energy storage systems in radial networks for wind power integration with reserve support. IET Gener. Transm. Distrib. 2016, 10, 2019-2025. [CrossRef]

8. Liu, G.; Ceylan, O.; Xiao, B.; Starke, M.; Ollis, B.; King, D.; Irminger, P.; Tomsovic, K. Advanced energy storage management in distribution network. In Proceedings of the 49th Hawaii International Conference on System Sciences, Koloa, HI, USA, 5-8 January 2016; pp. 2381-2389.

9. Lujano-Rojas, J.; Dufo-Lopez, R.; Bernal-Agustin, J.; Catalão, J.P.S. Optimizing daily operation of battery energy storage systems under real-time pricing schemes. IEEE Trans. Smart Grid 2017, 8, 316-330. [CrossRef]

10. Zhou, T.; Sun, W. Optimization of battery-supercapacitor hybrid energy storage station in wind/solar generation system. IEEE Trans. Sustain. Energy 2014, 5, 408-415. [CrossRef]

11. Baños, R.; Manzano-Agugliaro, F.; Montoya, F.G.; Gil, C.; Alcayde, A.; Gómez, J. Optimization methods applied to renewable and sustainable energy: A review. Renew. Sustain. Energy Rev. 2011, 15, 1753-1766. [CrossRef]

12. Xiao, H.; Pei, W.; Dong, Z.; Kong, L.; Wang, D. Application and comparison of metaheuristic and new metamodel based global optimization methods to the optimal operation of active distribution networks. Energies 2018, 11, 85. [CrossRef]

13. Wang, G.; Ciobotaru, M.; Agelidis, V.G. Power smoothing of large solar PV plant using hybrid energy storage. IEEE Trans. Sustain. Energy 2014, 5, 834-842. [CrossRef]

14. Kollimalla, S.K.; Mishra, M.K.; Lakshmi, N.N. Coordinated control and energy management of hybrid energy storage system in PV system. In Proceedings of the IEEE International Conference on Computation of Power, Energy, Information and Communication, Chennai, India, 16-17 April 2014; pp. 363-368.

15. Liu, X.; Aichhorn, A.; Liu, L.; Li, H. Coordinated control of distributed energy storage system with tap changer transformers for voltage rise mitigation under high photovoltaic penetration. IEEE Trans. Smart Grid 2012, 3, 897-906. [CrossRef]

16. Trung, T.T.; Ahn, S.J.; Choi, J.H.; Go, S.I.; Nam, S.R. Real-time wavelet-based coordinated control of hybrid energy storage systems for denoising and flattening wind power output. Energies 2014, 7, 6620-6644. [CrossRef]

17. Jiang, Q.; Hong, H. Wavelet-based capacity configuration and coordinated control of hybrid energy storage system for smoothing out wind power fluctuations. IEEE Trans. Power Syst. 2013, 28, 1363-1372. [CrossRef]

18. Kabir, M.N.; Mishra, Y.; Ledwich, G.; Dong, Z.Y.; Wong, K.P. Coordinated control of grid-connected photovoltaic reactive power and battery energy storage systems to improve the voltage profile of a residential distribution feeder. IEEE Trans. Ind. Inform. 2014, 10, 967-977. [CrossRef]

19. Wang, Y.; Tan, K.T.; Peng, X.Y.; So, P.L. Coordinated control of distributed energy-storage systems for voltage regulation in distribution networks. IEEE Trans. Power Deliv. 2016, 31, 1132-1141. [CrossRef]

20. Mokhtari, G.; Nourbakhsh, G.; Ghosh, A. Smart coordination of energy storage units (ESUs) for voltage and loading management in distribution networks. IEEE Trans. Power Syst. 2013, 28, 4812-4820. [CrossRef]

21. Zillmann, M.; Yan, R.; Saha, T.K. Regulation of distribution network voltage using dispersed battery storage systems: A case study of a rural network. In Proceedings of the IEEE Power and Energy Society General Meeting, Detroit, MI, USA, 24-29 July 2011; pp. 1-8.

22. Zhao, B.; Zhang, X.; Chen, J.; Wang, C.; Guo, L. Operation optimization of standalone microgrids considering lifetime characteristics of battery energy storage system. IEEE Trans. Sustain. Energy 2013, 4, 934-943. [CrossRef]

23. Fossati, J.P.; Galarza, A.; Martin-Villate, A.; Fontán, L. A method for optimal sizing energy storage systems for microgrids. Renew. Energy 2015, 77, 539-549. [CrossRef] 
24. Wang, J.; Liu, P.; Hicks-Garner, J.; Sherman, E.; Soukiazian, S.; Verbrugge, M.; Tataria, H.; Musser, J.; Finamore, P. Cycle-life model for graphite-LiFePO4 cells. J. Power Sources 2011, 196, 3942-3948. [CrossRef]

25. Xu, B.; Oudalov, A.; Ulbig, A.; Andersson, G.; Kirschen, D. Modeling of lithium-Ion battery degradation for cell life assessment. IEEE Trans. Smart Grid 2016, PP, 1. [CrossRef]

26. Uno, M.; Tanaka, K. Accelerated charge-discharge cycling test and cycle life prediction model for supercapacitor in alternative battery applications. IEEE Trans. Ind. Electron. 2012, 59, 4704-4712. [CrossRef]

27. Hammar, A.; Venet, P.; Lallemand, R.; Coquery, G.; Rojat, G. Study of accelerated aging of supercapacitors for transport applications. IEEE Trans. Ind. Electron. 2010, 57, 3972-3979. [CrossRef]

28. Spotnitz, R. Simulation of capacity fade in lithium-ion batteries. J. Power Sources 2003, 113, 72-80. [CrossRef]

29. Brenna, M.; Berardinis, E.D.; Carpini, L.D.; Foiadelli, F.; Paulon, P.; Petroni, P.; Sapienza, G.; Scrosati, G.; Zaninelli, D. Automatic distributed voltage control algorithm in smart grids applications. IEEE Trans. Smart Grid 2013, 4, 877-885. [CrossRef]

30. Wang, P.; Liang, D.H.; Yi, J.; Lyons, P.F.; Davison, P.J.; Taylor, P.C. Integrating electrical energy storage into coordinated voltage control schemes for distribution networks. IEEE Trans. Smart Grid 2014, 5, 1018-1032. [CrossRef]

31. Pudjianto, D.; Aunedi, M.; Djapic, P.; Strbac, G. Whole-systems assessment of the value of energy storage in low-carbon electricity systems. IEEE Trans. Smart Grid 2014, 5, 1098-1109. [CrossRef]

32. Black, M.; Strbac, G. Value of bulk energy storage for managing wind power fluctuations. IEEE Trans. Energy Convers. 2007, 22, 197-205. [CrossRef]

33. Glavin, M.E.; Chan, P.K.W.; Armstrong, S.; Hurley, W.G. A stand-alone photovoltaic supercapacitor battery hybrid energy storage system. In Proceedings of the 13th IEEE Power Electronics and Motion Control Conference, Poznan, Poland, 1-3 September 2008; pp. 1688-1695.

34. Teleke, S.; Baran, M.E.; Bhattacharya, S.; Huang, A.Q. Rule-based control of battery energy storage for dispatching intermittent renewable sources. IEEE Trans. Sustain. Energy 2010, 1, 117-124. [CrossRef]

35. Kumar, R.S.; Kumar, K.S.; Mishra, M.K. Dynamic energy management of micro grids using battery super capacitor combined storage. In Proceedings of the Annual IEEE India Conference (INDICON), Kochi, India, 7-9 December 2012; pp. 1078-1083.

36. Gabash, A.; Li, P. Active-reactive optimal power flow in distribution networks with embedded generation and battery storage. IEEE Trans. Power Syst. 2012, 27, 2026-2035. [CrossRef]

37. Atwa, Y.M.; EI-Saadany, E.F. Probabilistic approach for optimal allocation of wind-based distributed generation in distribution systems. IET Renew. Power Gener. 2011, 5, 79-88. [CrossRef] 